\title{
A compra e venda de vestuário on-line: comunicando atributos não- digitais em um meio digital e a relação com o design e a UX
}

\author{
Selling and buying apparel online: communicating non-digital attributes \\ through digital media and the relation with design and UX
}

\author{
BOZZI, Carolina \\ Centro de Investigação em Arquitetura, Urbanismo e Design, Faculdade de Arquitetura, \\ Universidade de Lisboa, Doutoranda \\ carolbozzi@gmail.com
}

\begin{abstract}
NEVES, Marco
Centro de Investigação em Arquitetura, Urbanismo e Design, Faculdade de Arquitetura, Universidade de Lisboa, D. Sc.

mneves@fa.ulisboa.pt
\end{abstract}

MONT'ALVÃO, Claudia

Programa de Pos Graduação em Design, PUC-Rio | LEUI, D. Sc.

cmontalvao@puc-rio.br

\section{RESUMO}

Artigos de vestuário são produtos com os quais as pessoas ainda sentem a necessidade de ter um contato multissensorial. Alguns de seus atributos são dificilmente comunicados digitalmente, como a textura e o caimento do tecido, ademais, a falta de padronização de tamanhos praticada pela indústria suscita diversas dúvidas no consumidor/usuário, levando-o, em determinadas situações, a comprar produtos e serviços que não suprem suas necessidades ou expectativas. Essa situação gera frustração e o aumento no número de devoluções. Pretende-se por meio do design de interação e do design de informação, criar diretrizes visando o desenvolvimento de websites com uma usabilidade otimizada, a oferecer o suporte necessário à jornada do usuário e à sua experiência de compra. $O$ estudo apresentado faz parte de uma investigação de doutorado em andamento e tem como objetivo geral melhorar a relação e a experiência do usuário (UX) ao interagir com websites de comércio eletrônico de vestuário feminino. Objetiva-se com este artigo promover uma discussão preliminar acerca das dificuldades em comunicar-se certos atributos do vestuário por meio da internet. Espera-se, ao final da investigação, aprimorar a qualidade da interação dos usuários com as apresentações dos produtos de vestuário vendidos on-line, de forma a torná-la mais eficiente, eficaz e satisfatória. Consequentemente os usuários poderão tomar decisões de compra com mais consciência e segurança.

Design, UX, usabilidade, e-commerce, vestuário. 


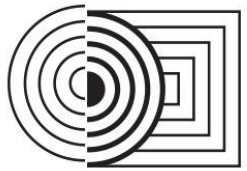

\section{$17^{\circ}$ ERGODESIGN \& USIHC 2019 \\ PUC-Rio, 11 a 13 de dezembro \\ Rio de Janeiro, RJ, Brasil}

$17^{\circ}$ Ergodesign - Congresso Internacional de Ergonomia e Usabilidade de Interfaces Humano Tecnológica: Produto, Informações Ambientes Construídos e Transporte

$17^{\circ}$ USIHC - Congresso Internacional de Ergonomia e Usabilidade de Interfaces Humano Computador

\begin{abstract}
People still feel the need for a multi-sensory contact with clothing products. Some of its attributes are difficult to communicate digitally, such as the texture and the fit of the fabric. Moreover, the lack of size standardisation practiced by the industry raises several doubts for the consumer/user, leading them, in certain situations, to buy products and services that do not meet their needs or expectations. This situation generates frustration and the increase the return rates. The goal is to create guidelines for the development of websites with optimised usability, through interaction design and information design, to provide the necessary support for the user's journey and shopping experience. The study presented is part of an ongoing doctoral research and aims to improve the relationship and user experience (UX) when interacting with women's apparel e-commerce websites. This article aims to promote a preliminary discussion about the difficulties in communicating certain attributes of clothing on the internet. By the end of the research, it is expected to improve the quality of user interaction with the presentations of clothing sold online in order to make it more efficient, effective and satisfying. As a result users will be able to make more informed and secure purchasing decisions.
\end{abstract}

Design, UX, usability, e-commerce, apparel.

\title{
1. INTRODUÇÃO
}

Com o objetivo de levantar quais são os obstáculos mais relevantes encontrados por consumidores ao comprarem peças de vestuário on-line, Bozzi (2018) desenvolveu uma pesquisa em que se verificou que um dos principais problemas relacionados às compras de roupas on-line, realizadas no Brasil está ligado à falta de confiança nas informações apresentadas nos websites. A investigadora utilizou-se de uma série de métodos empíricos para compreender o processo de compra de roupas e os modelos mentais dos utilizadores, dentre eles, testes de usabilidade.

Durante os testes foi possível observar dificuldades por parte dos usuários no processo de compra on-line de peças de vestuário. Esta dificuldade foi percebida mesmo antes da interação com o sistema afetando a expectativa do usuário influenciando a sua experiência. A experiência do usuário, ou a UX, são as percepções e respostas dos utilizadores resultantes do uso e/ou antecipação do uso de um produto, sistema ou serviço (International Standard Organization [ISO], 2010).

Percebeu-se que existe uma barreira entre os ambientes físico e digital advinda da falta de contato físico prévio com o produto, a impedir o usuário de fazer uma inspeção completa. Um dos fatores que contribui para a existência desta barreira é a incerteza quanto ao ajuste e ao caimento das peças. Apesar de algumas iniciativas da indústria e dos órgãos de normatização, tais como a Associação Brasileira de Normas Técnicas [ABNT] (1995; 2002; 2004; 2009), no Brasil, e a ISO (1991), os varejistas não seguem uma única referência para a construção das suas tabelas de tamanhos. As diferentes tabelas de tamanhos adotadas pelas empresas de vestuário dificultam a tomada de decisão dos usuários on-line por não terem certeza qual tamanho deve ser selecionado e se a peça, uma vez entregue em seu domicílio, venha a ter bom caimento e se terá o tamanho adequado ao corpo do consumidor.

Os problemas relacionados aos tamanhos dos artigos de vestuário oferecem-nos uma série de fatores a considerar (DINIS; VASCONCELOS, 2014). A falta de padronização do processo de desenvolvimento de modelagem pode ser percebida claramente em produtos de uma mesma empresa. Gera-se confusão no estabelecimento de tamanhos das peças a refletir-se 


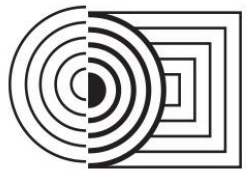

\section{$17^{\circ}$ ERGODESIGN \& USIHC 2019 \\ PUC-Rio, 11 a 13 de dezembro \\ Rio de Janeiro, RJ, Brasil}

$17^{\circ}$ Ergodesign - Congresso Internacional de Ergonomia e Usabilidade de Interfaces Humano Tecnológica: Produto, Informações Ambientes Construídos e Transporte

$17^{\circ}$ USIHC - Congresso Internacional de Ergonomia e Usabilidade

de Interfaces Humano Computador

diretamente no processo de decisão de compra do consumidor. Existem casos de consumidores que adquirem produtos na mesma loja com variações de até três manequins (DINIS; VASCONCELOS, 2014). De uma forma geral, tem-se a percepção que essa disparidade acontece mais no vestuário feminino. Segundo Chun (2007), as mulheres relatam mais problemas do que os homens. A propósito, a autora argumenta que isto deve-se em parte a uma grande variedade de formas e de estilos disponíveis no vestuário feminino.

Todavia, os usuários de websites de comércio eletrônico de vestuário também não se sentem seguros com as informações apresentadas acerca dos produtos, principalmente atributos que se referem ao tamanho e caimento. Existe uma assimetria da informação, quando os vendedores/varejistas detêm mais dados acerca do produto do que os consumidores, (AKERLOF, 1970; MAVLANOVA; BENUBAN-FICH; KOUFARIS, 2012) acentuada pela falta de contato físico com o produto que é vista como um fator que dificulta ou impede a compra online. As roupas têm textura e caimento, qualidades difíceis de serem transmitidas por uma tela (BELL, 2016), são atributos não-digitais de um produto, há perda de informação quando comunicados digitalmente (LAL; SAVARY, 1999). Objetiva-se com este artigo promover uma discussão preliminar acerca das dificuldades em comunicar-se esses atributos não-digitais em uma mídia digital, como a internet. Os websites de comércio eletrônico devem assegurar no mínimo o mesmo nível de segurança que um consumidor sente ao comprar em uma loja física (VITOR; NERY; MOREIRA, 2016), fornecendo aos usuários informações suficientes e claras para que possam ter suporte no seu processo decisório de compra.

\section{FUNDAMENTAÇÃO TEÓRICA 2.1. Atributos não digitais}

A categoria de Roupas e Acessórios está entre as mais compradas tanto no Brasil (E-BIT, 2018) quanto na Europa (POSTNORD, 2018) e em Portugal (DPDGROUP, 2019). Contudo, os produtos de vestuário são os mais devolvidos pelos consumidores europeus, somente no Reino Unido, estima-se que aproximadamente $50 \%$ do valor gasto é reembolsado aos compradores à medida em que os produtos são retornados. No Brasil, $84 \%$ dos usuários ficam desmotivados a comprar peças de vestuário on-line por não poderem experimentá-las ou vê-las fisicamente (Figura 1), aponta um relatório do Serviço Brasileiro de Apoio às Micro e Pequenas Empresas do Rio de Janeiro [SEBRAE-RJ] (2015). Este comportamento ocorre possivelmente do fato de que as peças de vestuário são produtos com mais atributos não-digitais do que digitais.

Figura 1: Fatores que desmotivam as compras on-line. Fonte: (SEBRAE-RJ, 2015, p. 2)

FATORES QUE DESMOTIVAM AS COMPRAS ON-LINE

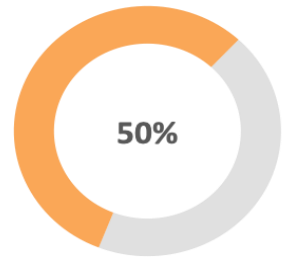

Medo de não receber o que foi comprado

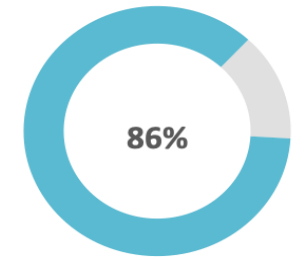

Não poder experimentar ou ver fisicamente aquilo que irá comprar 


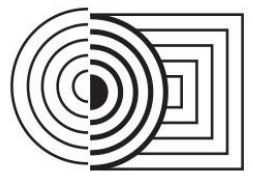

\section{$17^{\circ}$ ERGODESIGN \& USIHC 2019 \\ PUC-Rio, 11 a 13 de dezembro \\ Rio de Janeiro, RJ, Brasil}

$17^{\circ}$ Ergodesign - Congresso Internacional de Ergonomia e Usabilidade de Interfaces Humano Tecnológica: Produto, Informações Ambientes Construídos e Transporte

$17^{\circ}$ USIHC - Congresso Internacional de Ergonomia e Usabilidade de Interfaces Humano Computador

A categoria de atributos não-digitais inclui características que só podem ser avaliadas por meio do contato físico. No âmbito do vestuário, a textura e o ajuste ao corpo, características chaves para a avaliação do produto pelo consumidor, só podem ser verificadas por meio de um contato tátil e, portanto, físico. Perceba-se que, o ajuste de uma camisa, quando apresentado ou descrito on-line, pode suscitar incertezas significativas para determinados consumidores. Logo, dependendo do canal utilizado, os consumidores podem não ter informações completas antes de realizarem uma compra.

A impossibilidade dos consumidores de tocar produtos com atributos não-digitais anterior a compra on-line pode:

1. Atuar como dissuasor para a compra; e

2. Aumentar os custos operacionais derivados das devoluções, quando há uma discrepância entre a expectativa e a realidade (LAL; SARVARY, 1999).

Do ponto de vista do design centrado no usuário, quando um produto não atende às expectativas, contribui para uma UX negativa. A falta de informação e da interação física com o produto são algumas das principais barreiras à compra on-line. Em Portugal, entre os 8 motivos identificados a desestimular compras on-line, 4 estão relacionados à falta de informações suficientes ou claras sobre o produto ou sobre o processo de compra (CTT, 2018). A descrição detalhada de produtos é considerada um critério importante para a compra on-line por $92 \%$ dos portugueses (DPDGROUP, 2019). No caso das peças de vestuário, estas requerem um contato multissensorial, verifica-se que essa falta de interação direta pode levar a uma menor satisfação do consumidor no processo de compras e a uma maior percepção de risco (BLÁZQUEZ, 2014).

As peças de vestuário também podem ser classificadas como bens de experiência. Nos anos dos 1970, Philip Nelson desenvolveu um conceito para categorizar bens de consumo em dois grupos: os de pesquisa (search goods) e os de experiência (experience goods). Os bens de pesquisa não exigem que os consumidores os experimentem antes da compra, suas características são-Ihes familiares ou facilmente percebidas (NELSON, 1970). Portanto, antes de comprar um bem de pesquisa, o consumidor é capaz de perceber se há diferenças entre a descrição anunciada e o produto real. Este tipo de situação dá-se na compra on-line, o consumidor avalia o produto com base nas fotos e descrições apresentadas. Logo, quando se trata de um bem de pesquisa o consumidor pode fazer uma avaliação completa do produto. No caso dos bens de experiência, o poder do consumidor sobre as descrições é muito menor do que sobre as dos bens de pesquisa (NELSON, 1974). Os bens de experiência exigem que sejam experimentados antes da compra pelos consumidores para que estes tenham uma opinião real a respeito.

Apesar dos conceitos de atributos digitais e não digitais e bens de busca e de experiência terem sido criados nos anos dos 1970 e dos 1990, ainda são utilizados por estudiosos de mercado de bens de consumo, tais como: Bell, Gallino e Moreno (2016).

\subsection{Design de interação}

As interações humano-humano estão gradualmente sendo substituídas por aquelas por meio de interfaces digitais introduzindo novas modalidades de interação com os consumidores. Os terminais de auto-atendimento em supermercados e aeroportos onde os próprios utilizadores precisam fazer realizar pagamentos, entre outras tarefas, estão a tornar-se a norma, as 


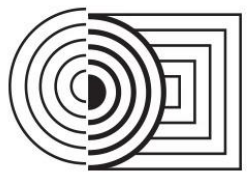

\section{$17^{\circ}$ ERGODESIGN \& USIHC 2019 \\ PUC-Rio, 11 a 13 de dezembro \\ Rio de Janeiro, RJ, Brasil}

$17^{\circ}$ Ergodesign - Congresso Internacional de Ergonomia e Usabilidade de Interfaces Humano Tecnológica: Produto, Informações Ambientes Construídos e Transporte

$17^{\circ}$ USIHC - Congresso Internacional de Ergonomia e Usabilidade de Interfaces Humano Computador

interfaces digitais estão gradualmente a substituir os humanos. Embora, frequentemente, seja mais econômico, coloca-se o ônus nos usuários em ter de interagir com sistemas no lugar de com outro humano. Executar um comando errado pode resultar em uma experiência frustrante e às vezes com consequências difíceis de serem revertidas, especialmente para àqueles que são iniciantes (PREECE; ROGERS; SHARP, 2015). O objetivo principal do design de interação é o de reduzir esses aspectos negativos da experiência do usuário e o de aprimorar seus aspectos positivos. Trata-se de desenvolver produtos interativos centrados no usuário que sejam fáceis, eficazes e agradáveis de usar (PREECE; ROGERS; SHARP, 2015).

Segundo Moggridge (2007), o design de interação abrange tudo o que é tanto digital e interativo. Inclui todas as interações que são permitidas pela tecnologia digital, seja por meio de um computador, um microchip inserido em um produto ou ambiente, de serviços ou da internet. Seguindo as visões de Davis (2008) e Buchanan (1998), Dubberly, Pangaro e Haque (2009) argumentam que a interação é uma forma de estabelecer uma relação entre pessoas e os objetos concebidos para o seu uso e por consequência estabelece o contexto da atividade do design. Os autores explicam que é possível interagir com todos os objetos criados pelos humanos, e todas as atividades de design podem ser vistas como interação. O mesmo vale não somente para objetos, como também para espaços, mensagens e sistemas. Em suma, o design de interação envolve projetar produtos interativos para apoiar a maneira como as pessoas se comunicam e interagem em suas vidas cotidianas e profissionais (PREECE; ROGERS; SHARP, 2015).

Preece, Rogers e Sharp (2015), propõem quatro tipos de interação. Ressalta-se que podem acontecer simultaneamente; as interações com sistemas podem ser baseadas em diferentes tipos de atividades, são eles:

- Instruir - os usuários emitem instruções para um sistema, como: digitar comandos, selecionar opções de menus, comandos de voz, gestos, pressionar botões ou usar uma combinação de teclas.

- Conversar - quando os usuários dialogam com um sistema. Pode ocorrer pela fala por meio de uma interface ou ao digitar perguntas para as quais o sistema responde utilizando texto ou voz.

- Manipular - acontece quando os usuários interagem com objetos em um espaço virtual ou físico manipulando-os (abrindo, segurando, fechando, posicionando). Os usuários podem aprimorar seu conhecimento de como interagir com objetos.

- Explorar - os usuários se movem através de um ambiente virtual ou um espaço físico. Ambientes virtuais incluem mundos 3D e sistemas de realidade aumentada e virtual. Eles permitem que os usuários aprimorem seu conhecimento de movimentação física.

Portanto, há uma infinidade de escolhas e decisões que os designers de interação precisam de fazê-las e de tomá-las para uma gama cada vez maior de produtos, e idealmente seguindo alguns passos durante o processo de design, tais como:

- Levar em conta o que as pessoas são boas e ruins. 
$17^{\circ}$ ERGODESIGN \& USIHC 2019

PUC-Rio, 11 a 13 de dezembro

Rio de Janeiro, RJ, Brasil $17^{\circ}$ Ergodesign - Congresso Internacional de Ergonomia e Usabilidade de Interfaces Humano Tecnológica: Produto, Informações Ambientes Construídos e Transporte

$17^{\circ}$ USIHC - Congresso Internacional de Ergonomia e Usabilidade

de Interfaces Humano Computador

- Considerar o que pode ajudar as pessoas no modo como elas atualmente fazem as coisas.

- Pensar em fornecer experiências de qualidade para o usuário.

- Ouvir o que as pessoas querem e envolvê-las no design.

- Utilizar técnicas testadas e experimentadas pelo usuário durante o processo de design.

\subsection{Problemas ao comprar roupas on-line}

Os seguintes problemas, por parte dos usuários, foram revelados ao longo da investigação de mestrado supracitada (BOZZI, 2018):

- Não confiam nas informações apresentadas em websites de comércio eletrônico;

- Não compram on-line; pois não se sentem seguros em relação ao caimento das roupas e tampouco quanto ao tamanho das peças (não sabem se os tamanhos apresentados correspondem à realidade, haja vista a disparidade de medidas existente na indústria);

- Não confiam ou não compreendem as informações de medidas das peças;

- Desconhecem termos técnicos - falta conhecimento técnico para entenderem e traduzirem as informações acerca dos tecidos utilizados assim como para identificarem os diferentes grupos de vestuário;

- A compreensão das informações é diferente ao utilizarem um desktop/laptop ou um dispositivo móvel;

- Têm uma percepção de que não há informações suficientes para dar suporte aos seus processos de decisão de compra;

- São influenciados positivamente ou negativamente pelas fotos dos produtos;

- A maioria utiliza-se de dados de compras anteriores como suporte ao processo decisório;

- Têm dificuldade em compreender as descrições dos atributos não digitais.

\subsection{O design de informação como ferramenta para auxiliar a compra on-line}




\section{$17^{\circ}$ ERGODESIGN \& USIHC 2019}

PUC-Rio, 11 a 13 de dezembro

Rio de Janeiro, RJ, Brasil $17^{\circ}$ Ergodesign - Congresso Internacional de Ergonomia e Usabilidade de Interfaces Humano Tecnológica: Produto, Informações Ambientes Construídos e Transporte

$17^{\circ}$ USIHC - Congresso Internacional de Ergonomia e Usabilidade de Interfaces Humano Computador

Por causa do desenvolvimento das mídias digitais durante os últimos anos, é necessária uma reflexão acerca da forma como as informações estão a ser apresentadas aos usuários com o intuito de facilitar a sua compreensão. Observe-se, ao comprar on-line, os usuários não têm um contato físico prévio com o produto, as peças de vestuário, em particular, possuem muitos atributos não digitais e, portanto, elaborar sua descrição pode ser um desafio para vendedores e de difícil compreensão para os consumidores. Some-se a isto a questão relacionada aos tamanhos praticados pela indústria da moda. As empresas acabam por adotar suas próprias tabelas ao visar a um público alvo específico e isso gera confusão no consumidor que não sabe exatamente qual tamanho de roupa está de fato comprando. Nas Figuras 2 e 3 pode verificar-se as diferentes medidas adotadas por duas empresas, para Ashdown (2014), empresas devem fornecer uma interface apropriada; um método eficaz de comunicação dos sistemas de medidas adotados de forma que o consumidor possa fazer a seleção do tamanho desejado e que o processo de escolha e validação do tamanho correto seja eficiente.

Objetivando comunicar mais eficientemente os atributos dos produtos de vestuário, considerase o design de informação como ferramenta para atingir este objetivo. Essa área do design é primeiramente o resultado da organização eficaz de dados para transformá-los em informação e então desenvolver um instrumento (ex.: um mapa ou uma página de um website) para transferir tais informações de forma a aumentar a base de conhecimento do usuário ou de orientar o desempenho da tarefa pretendida de maneira eficaz e convincente (ZWAGA; BOERSEMA; HOONHOUT, 2014). 


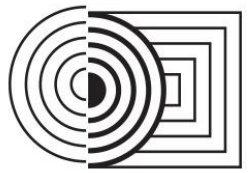

\section{$17^{\circ}$ ERGODESIGN \& USIHC 2019 \\ PUC-Rio, 11 a 13 de dezembro}

Rio de Janeiro, RJ, Brasil

$17^{\circ}$ Ergodesign - Congresso Internacional de Ergonomia e Usabilidade de Interfaces Humano Tecnológica: Produto, Informações Ambientes Construídos e Transporte

$17^{\circ}$ USIHC - Congresso Internacional de Ergonomia e Usabilidade

de Interfaces Humano Computador

Figuras 2 e 3: Exemplos de tabelas de medidas femininas. Fonte: renner.com.br; cea.com.br; recuperado em 10

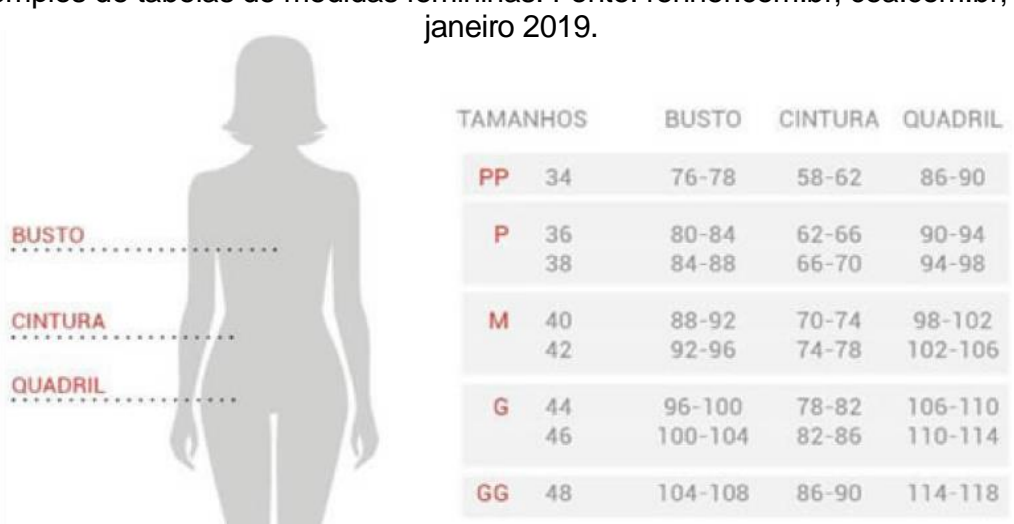

Na dúvida sobre que tamanho comprar?

Vocè pode trocar suas compras em qualquer uma de nossas lojas ou pelo site, sem nenhum custo.

- As medidas referem-se ao corpo e nào à roupa.

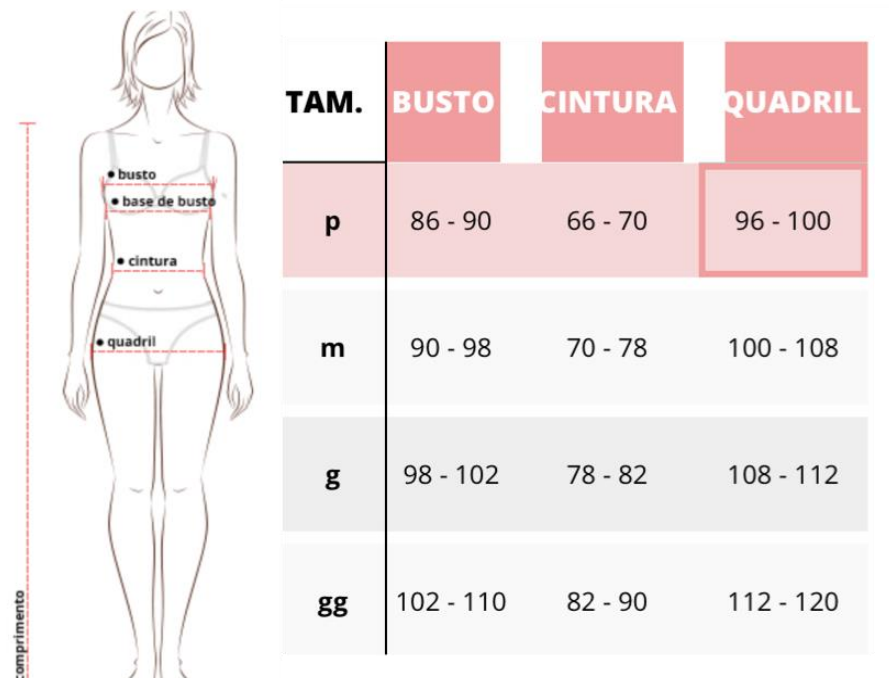

Segundo Horn (1999), o design de informação é definido como a arte e a ciência da preparação da informação para que possa ser usada pelos humanos com eficiência e eficácia. Seus principais objetivos são:

1. Desenvolver documentos que sejam compreensíveis, rápida e precisamente recuperáveis e fáceis de traduzir em ações efetivas;

2. Projetar interações com equipamentos que sejam fáceis, naturais e tão agradáveis quanto possível. Isso envolve a solução de muitos problemas no design da interface humanocomputador; e

3. Permitir que as pessoas encontrem seu caminho no espaço tridimensional com conforto e facilidade especialmente no espaço urbano como também, no espaço virtual.

Para Horn (1999), os valores que distinguem o design de informação de outros tipos de design são a eficiência e a eficácia no cumprimento do propósito comunicativo. Quando um 


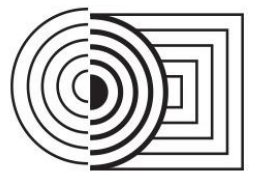

\section{$17^{\circ}$ ERGODESIGN \& USIHC 2019 \\ PUC-Rio, 11 a 13 de dezembro \\ Rio de Janeiro, RJ, Brasil}

$17^{\circ}$ Ergodesign - Congresso Internacional de Ergonomia e Usabilidade de Interfaces Humano Tecnológica: Produto, Informações Ambientes Construídos e Transporte

$17^{\circ}$ USIHC - Congresso Internacional de Ergonomia e Usabilidade de Interfaces Humano Computador

consumidor seleciona uma peça de roupa ready-to-wear, uma etiqueta de tamanho fornece informações sobre as dimensões da peça antes do consumidor experimentá-la. A etiqueta de tamanho é um canal de comunicação entre o fabricante e os consumidores, para que estes possam tomar decisões de compra eficientes (CHUN, 2007). A comunicação da informação acerca do ajuste e do tamanho das peças de roupas é fundamental para o desenvolvimento de um sistema eficaz. Se estas informações não forem confiáveis ou completas, impossibilitam o consumidor de identificar qual é o tamanho mais adequado em um determinado intervalo que se lhe ajuste, provocando repetidas visitas ao provador para experimentar tamanhos diferentes (ASHDOWN, 2014; CHUN, 2007).

No ambiente digital, as etiquetas são substituídas por descrições textuais e tabelas de medidas que são utilizadas na página de apresentação do produto ou em guias de tamanhos. Em um levantamento recente realizado pela pesquisadora, foram identificadas diversas questões relativas à dificuldade encontrada pelos consumidores para compreender as informações de tamanho contidas nas tabelas de tamanhos dos websites de vestuário. Para fins de ilustração, os Vídeos 1 e $2^{1}$ apresentam: uma tabela em que o consumidor perde o referencial da informação por causa da necessidade de fazer o scroll da tela; e uma segunda tabela que é extremamente pequena e que não é possível aumentá-la para ler o texto e deste modo impossibilita o acesso.

Uma etiqueta/tabela de tamanho só cumpre sua função, quando os consumidores a acham fácil e eficiente para selecionar roupas que se ajustem adequadamente a seus corpos (MASON et al., 2008). O quanto um consumidor sabe acerca de um produto, desempenha um papel importante no que diz respeito às suas expectativas. O seu conhecimento também se torna essencial, quando tem de avaliar o produto no ponto de venda, se está satisfeito ou insatisfeito, e para indicar onde reside a causa de sua insatisfação. Um consumidor com pouco entendimento quanto ao tamanho e medidas de uma peça de roupa não seria capaz de tomar decisões informadas. Sem o conhecimento adequado de suas próprias medidas corporais, das dimensões da peça e do significado da etiqueta de tamanho, o consumidor também não seria capaz de saber por que aquela não se ajusta corretamente e seria incapaz de corrigir o problema em compras futuras. Um consumidor que não tem suas expectativas atingidas, quando uma peça não se ajusta como era esperado, culpará o fabricante ou o varejista, e ficará frustrado. Os consumidores têm o direito a informações claras e compreensíveis sobre o que estão comprando (MASON et al., 2008).

Diante de um sistema complexo de tabelas de tamanho, é essencial concentrar esforços não só em apresentar aos consumidores descrições ricas e completas dos produtos como também em assisti-los a entender essa informação e fornecer meios para que possam utilizá-las (MASON et al.,2008). Sem a apreensão da informação não é possível a socialização do consumidor. Este conceito foi desenvolvido por Ward (1974) e é definido como o processo pelo qual jovens adquirem habilidades e conhecimento relevantes para a sua atuação no mercado como consumidores. Apesar do conceito inicial ter sido estabelecido pensando em jovens $e$ adolescentes e por formarem eles o conjunto de futuros consumidores; à época a preocupação era a de como dirigir as propagandas destinadas a esse público e de que maneira viriam a ser

\footnotetext{
1 Para consultar os vídeos, por favor, acesse os links abaixo:

Vídeo 1 - https://www.dropbox.com/s/peln01zstabyt3w/V\%C3\%ADdeo1_03-03-2019\%2013-43-41.mp4?dl=0

Vídeo 2: https://www.dropbox.com/s/fwdse3g5cv71603/V\%C3\%ADdeo2_03-03-2019\%2013-45-43.mp4?dl=0
} 


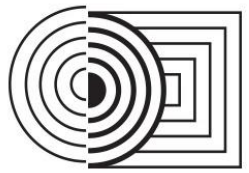

\section{$17^{\circ}$ ERGODESIGN \& USIHC 2019 \\ PUC-Rio, 11 a 13 de dezembro \\ Rio de Janeiro, RJ, Brasil}

$17^{\circ}$ Ergodesign - Congresso Internacional de Ergonomia e Usabilidade de Interfaces Humano Tecnológica: Produto, Informações Ambientes Construídos e Transporte

$17^{\circ}$ USIHC - Congresso Internacional de Ergonomia e Usabilidade

de Interfaces Humano Computador

afetados por elas. Estudos recentes já aplicam esse conceito aos adultos com o intuito de conhecer como adquirem informações para habilitarem-se e posicionarem-se como consumidores, ao longo de toda a vida e não somente quando jovens (MOREIRA; CASOTTI; CAMPOS, 2018).

\subsection{Página de apresentação do produto}

A página de apresentação é o espaço virtual destinado à descrição do produto com o intuito de que os consumidores possam ter acesso aos seus atributos e decidirem se satisfaz ou não às suas necessidades. Segundo a categorização de Magrath e McCormick (2012), estão listados abaixo alguns dos componentes comumente utilizados para que esse conteúdo seja apresentado no varejo on-line:

- Conteúdo informativo: são os textos cujo o propósito é o de informar o consumidor. As informações de produto de vestuário incluem: a cor, o preço, os cuidados com a manutenção da peça, a disponibilidade dos tamanho, a textura e o tipo de tecido.

- Conteúdo multimídia: visa a criar uma experiência interativa e multissensorial, a transferir informação para o consumidor e a oferecer satisfação, diversão e entretenimento. Estão incluídos: os vídeos e as imagens dos produtos, as imagens interativas (ferramentas de aproximação, modelos virtuais, etc.).

Websites que oferecem apenas uma imagem de um item em um fundo claro são menos atraentes para os clientes do que fotos de modelos usando o mesmo item, o que ajuda os consumidores a se verem usando roupas da moda (LE BON, 2015).

Como os consumidores on-line não podem tocar no tecido ou observar os detalhes do acabamento, as fotografias dos itens on-line devem ser muito claras e detalhadas. $O$ website também deve permitir aos compradores aumentar e girar a imagem do produto para determinar e apreciar sua qualidade e ajuste. Além disso, uma descrição detalhada do produto e suas diferentes opções (por exemplo, cores, tecidos, tamanhos) pode reduzir o risco de compra de um comprador on-line, aumentar o envolvimento e facilitar o processo de decisão de compra (LE BON, 2015).

A qualidade das informações apresentadas aos consumidores, seja visual ou textual é fundamental para a formação de uma imagem mental do produto. No varejo on-line, a apresentação eficaz de um produto não apenas é um fator atrativo para os consumidores, ela facilita a tomada de decisão de compra na ausência de um contato direto. Em um ambiente digital em que os consumidores não conseguem fazer uma inspeção completa de um produto anterior à compra, a apresentação do produto desempenha um papel fundamental na obtenção de respostas afetivas e cognitivas, impactando subsequentemente as experiências e os resultados de compras. A importância da apresentação de produtos on-line é intensificada para produtos como o vestuário que envolvem a experiência multi-sensorial como parte do processo de tomada de decisão do consumidor (KIM; LENNON, 2008; YOO; KIM, 2012).

\subsection{Vanity sizing}




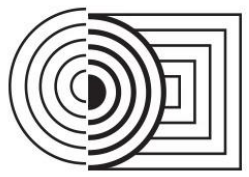

\section{$17^{\circ}$ ERGODESIGN \& USIHC 2019 \\ PUC-Rio, 11 a 13 de dezembro \\ Rio de Janeiro, RJ, Brasil}

$17^{\circ}$ Ergodesign - Congresso Internacional de Ergonomia e Usabilidade de Interfaces Humano Tecnológica: Produto, Informações Ambientes Construídos e Transporte

$17^{\circ}$ USIHC - Congresso Internacional de Ergonomia e Usabilidade de Interfaces Humano Computador

Outra fonte de confusão para os consumidores de vestuário é o vanity sizing ${ }^{2}$. Esta é uma prática comum entre as empresas de moda, consiste na manipulação das etiquetas das roupas (o tamanho impresso não corresponde ao real), com o objetivo de vender peças maiores como se fossem menores. Ashdown (2014) explica que como não há padrões obrigatórios de publicação de tamanhos em vários países, o número na etiqueta de tamanho pode ser escolhido por cada empresa para que possam utilizar suas próprias dimensões. A falta de dimensionamento consistente entre as empresas de vestuário pode ser confusa para o consumidor, este deve ser informado sobre quais medidas estão associadas às etiquetas de tamanho de cada empresa e qual é o tamanho delas para essa empresa em particular.

Apesar de alguns estudos indicarem que o vanity sizing conduz a avaliações positivas, com base no imaginário mental positivo que é evocado, quando os consumidores se visualizam em um tamanho menor (AYDINOĞLU; KRISHNA, 2012), é mais um fator que contribui para o problema de imprecisão dos sistemas de medidas de vestuário ready-to-wear. Acredita-se que as etiquetas são uma das razões para essa imprecisão quando se trata do tamanho do número de peças de vestuário em comparação com as medições reais e podem estar causando confusão e insatisfação desnecessárias entre as consumidoras (WEIDNER, 2010). E quando fazemos um paralelo com o ambiente digital, o correspondente as etiquetas de tamanho são as informações contidas nas descrições do produto, que, por vezes, são incompletas e refletem esta confusão causada pela prática do vanity sizing.

\subsection{Ferramentas que auxiliam a visualização dos produtos de vestuário}

Com o intuito de mitigar as questões expostas nos itens anteriores relacionadas ao dilema do tamanho e ajuste para o consumidor, têm surgido muitas tentativas comerciais para tentar resolvê-las. Gribbin (2014) lista algumas destas iniciativas tais como: o My Virtual Model, essa ferramenta permitia ao consumidor enviar suas medidas para um website para que então fosse criado um avatar personalizado de seu corpo. Outras como My Best Fit, Get My Size, and My True Fit baseavam-se em algoritmos e bancos de dados para converter as medidas corporais fornecidas pelos consumidores e sugestões de tamanho dentre as marcas disponíveis. My Shape e Fit Logic reconheceram que o formato do corpo era mais importante do que o tamanho ou até mesmo do que as medidas, mas identificar a forma correta e então encontrar um produto correspondente provou-se inviável. Algumas dessas tentativas iniciais de resolver o problema também não levaram em consideração as preferências pessoais de uso ou os fatores de erro no fornecimento das medidas pelos próprios consumidores (GRIBBIN, 2014).

É evidente que questões envolvendo tamanho e ajuste de peças de roupas são difíceis de abordar no contexto atual de produção de vestuário em massa; várias empresas continuam a propor soluções e a oferecer ferramentas com o intuito de tratar de forma mais individualizada os consumidores ao longo do processo de compra on-line. No entanto, essas soluções geralmente dependem do interesse do consumidor, da inserção de algumas de suas medidas corporais nos sistemas, da probabilidade de encontrar um item do tamanho e formato adequados e da disposição do consumidor de envolver-se neste processo antes da compra (GILL, 2015). Tanto as aplicações quanto os sistemas on-line para análise de ajuste virtual exigem alguns pormenores do formato do corpo e pressupõem que o usuário tenha entendimento suficiente para classificar seu próprio corpo (GILL, 2015) o que comumente não tem como identificado do estudo de Mason et al. (2008).

${ }^{2}$ T.L. - dimensionamento da vaidade. 


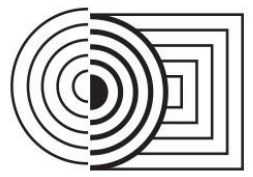

\section{$17^{\circ}$ ERGODESIGN \& USIHC 2019 \\ PUC-Rio, 11 a 13 de dezembro \\ Rio de Janeiro, RJ, Brasil}

$17^{\circ}$ Ergodesign - Congresso Internacional de Ergonomia e Usabilidade

de Interfaces Humano Tecnológica: Produto, Informações Ambientes Construídos e Transporte

$17^{\circ}$ USIHC - Congresso Internacional de Ergonomia e Usabilidade

de Interfaces Humano Computador

O conhecimento dos consumidores torna-se essencial, quanto às suas expectativas em relação aos produtos de vestuário, à maneira que eles escolhem e avaliam a qualidade dos produtos no ponto de venda e quando eles usam o produto. No momento em que os consumidores

percebem que suas expectativas não foram atendidas, sendo estas realistas ou irrealistas, que não há uma confirmação daquilo que esperavam do produto, levando-os a buscar razões para a ocorrência deste descompasso entre o que procuram e o que de fato estão a vestir (LAUFER, 2002).

A socialização do consumidor relacionada ao produto é importante para que os consumidores possam tomar decisões conscientes e responsáveis (MASON et al., 2008). Suas escolhas dependerão de sua experiência prévia com as roupas, o suporte que recebem das empresas de retalho, nível educacional e expectativas pessoais; a ignorância dos consumidores sobre quais medidas são necessárias ao escolher certas peças de roupa aumentariam suas dúvidas quanto ao ajuste das roupas (MASON et al., 2008).

Ser capaz de comparar as suas medidas e formas corporais para adequar-se aos indicadores contidos nas etiquetas de tamanho ou tabelas de medidas on-line reduziria a frustração do cliente (MASON et al., 2008). A comunicação de tamanho e ajuste deve ser legível, precisa e adequada para as diferentes categorias de vestuário e informar claramente as principais medidas (BROWN; RICE, 2001). Além de entender os códigos de tamanhos, os consumidores de vestuário devem saber quais medidas principais são usadas para construir determinada peça de roupa, bem como determinar suas próprias medidas corporais, a fim de fazer uma escolha de tamanho apropriada.

Mesmo com o vasto oferecimento de ferramentas, cujo objetivo é diminuir os problemas com a compreensão das informações acerca de tamanho e ajuste de uma peça de vestuário, estudos apontam que as simulações virtuais ainda não oferecem um nível fidelidade em face do produto real suficiente para resolver as dúvidas dos consumidores (KIM; LABAT, 2012).

Por outro lado, em outro estudo indica, que provadores virtuais utilizados em websites de ecommerce de vestuário são um potencial antídoto para o problema de devoluções (BELL; GALLINO; MORENO, 2014). Essas são tecnologias que fornecem aos consumidores on-line informações precisas e recomendações de tamanho antes de qualquer decisão de compra. A Metail, com sede em Londres, permite aos consumidores que criem um modelo 3D de si mesmos e avaliem como os produtos se ajustaram em seus corpos virtuais antes de efetuarem uma compra on-line. Em um projeto de investigação com a empresa, Bell, Gallino e Moreno (2014) exploraram, se a utilização de informações mais ricas fornecidas por esse tipo de ferramentas, resultaria em um aumento no volume de vendas e em menos devoluções. Os consumidores que tiveram acesso ao provador virtual, efetuaram mais compras e a consequência deste fato foram taxas de conversão mais altas e taxas de devolução mais baixas do que os clientes sem acesso àquela ferramenta. A propósito, percebe-se, então, que informações personalizadas de alta qualidade, mesmo quando fornecidas por meio de um canal on-line, são um poderoso aliado para reduzir as taxas de devolução do produto.

\section{CONCLUSÃO}

Esse artigo teve a intenção de promover uma discussão inicial acerca da dificuldade em comunicar-se certos atributos das peças de vestuário, assim como o caimento e textura de um tecido. Pretende-se ao longo da investigação de doutorado, da qual esse artigo deriva, 
encontrar meios que facilitem a troca de informações entre vendedores e consumidores, a torná-las mais eficientes e eficazes, além de contribuir com a investigações relacionadas ao comércio eletrônico e à UX, entre outras.

As diferentes áreas de conhecimento mencionadas - o design de interação e de informação, assim como: a ergonomia, a usabilidade e a experiência do usuário - formam uma rede de conhecimento e conceitos que serão aplicados para entender como aprimorar as páginas de apresentação de produtos de vestuário. Diferentes estudos colocam uma ou a outra como o guarda-chuva que abrange as outras. Porém o que elas têm em comum: visam ao protagonismo dos utilizadores dos sistemas e não ao contrário.

Existe um problema na comunicação dos atributos não digitais das peças de vestuário. Somada à dificuldade de transmitir-se determinadas características de uma roupa, como a textura do tecido, está a falta de padronização das medidas. O resultado são consumidores insatisfeitos e uma UX negativa. Os varejos de moda estão recorrendo a diversos meios, como as estratégias omnichannel e ferramentas tecnológicas para tentar resolver de forma agressiva um problema que além de prejudicial à indústria também o é para a UX.

O varejo on-line fornece um ambiente interativo no qual é possível utilizar ferramentas para facilitar a visualização dos produtos à venda. Um número crescente de varejistas de vestuário on-line começou a adotar ferramentas de visualização inovadoras como uma tentativa de satisfazer a necessidade dos consumidores de ter uma experiência multissensorial com os produtos.

As empresas de vestuário precisam conquistar a confiança dos consumidores se quiserem transformá-los em clientes regulares. De modo que todas as apresentações de vestuário de moda on-line, sejam imagéticas ou textuais, devem ser precisas, relevantes e consistentes com o produto (LE BON, 2015).

\section{REFERÊNCIAS BIBLIOGRÁFICAS}

ABNT (Associação Brasileira de Normas Técnicas). NBR 13377: medidas do corpo humano para vestuário - padrões referenciais. Rio de Janeiro: ABNT, 1995.

NBR 9241-11: requisitos ergonômicos para trabalho de escritório com computadores.

Parte 11: Orientações sobre usabilidade. Rio de Janeiro: ABNT, 2002.

. NBR 15127: corpo humano - definição de medidas. Rio de Janeiro: ABNT, 2004.

NBR 15800: vestuário - referência de medidas do corpo humano - vestibilidade de

roupas para bebê e infanto-juvenil. Rio de Janeiro, 2009.

ARKELOF, G. A. The market for "lemons": quality uncertainty and the market mechanism. The

Quarterly Journal of Economics v. 84, n. 3, p. 488-500, 1970.

ASHDOWN, S. P. Creation of ready-made clothing: the development and future of sizing systems.. In:

Faust, M. E.; Carrier, S. (Eds.). Designing apparel for consumers the impact of body shape and size.

Woodhead Publishing Series in Textiles: N.151. Philadelphia: Woodhead Publishing, 2014, p. 17-34.

AYDINOĞLU, N.; KRISHNA, A. Why vanity sizing works. Journal of Consumer Psychology n. 22. p. 565-

572, 2012.

$B E L L, D$. Localização (ainda) é tudo: como vender mais usando a influência do

mundo real sobre os hábitos de compra na internet. Tradução Bruno Alexander.

São Paulo: HSM do Brasil, 2016. 
BELL, D. R.; GALLINO, S.; MORENO, A. How to Win in an Omnichannel World. MIT Sloan Management

Review. v. 56, n.1, p. 44-53, 2014.

BELL, D. R.; GALLINO, S.; MORENO, A. Offline Showrooms in Omnichannel Retail: Demand and

Operational Benefits. Management Science, p. 1-43, 2016.

BLÁZQUEZ, M. Fashion Shopping in Multichannel Retail: The Role of Technology in Enhancing the

Customer Experience. International Journal of Electronic Commerce. v. 18, n. 4, p. 97-116, 2014.

$\mathrm{BOZZI}, \mathrm{C}$. M. A experiência do usuário (UX) em sítios de comércio: um estudo

ergonômico. 2018. 271 f. Dissertação (Mestrado em Design)- Programa de Pós-graduação em

Design do Departamento de Artes e Design, Pontifícia Universidade Católica do Rio de Janeiro,

Rio de Janeiro, 2018.

BUCHANAN, R. Branzi's dilemma: design in contemporary culture. Design Issues v.14, n.1, 1998.

BROWN, P.; RICE, J. Ready-To-Wear Apparel Analysis. (3rd ed.). New Jersey: Prentice Hall. Buchanan, 2001.

CHUN, J. Communication of sizing and fit. In: Ashdown, S. P. (Org.). 2007. Sizing in clothing: developing effective sizing systems for ready-to-wear clothing. Cambridge: Woodhead Publishing. p. 220-243, 2007.

CORREIOS DE PORTUGAL. e-Commerce Report CTT 2018. 2019. Disponível em:

$<$ https://www.ctt.pt>. Acesso em: 7 janeiro 2019.

DAVIS, M. Toto, I've Got a Feeling We're Not in Kansas Anymore... Interactions, v. 15, n. 5, 2008.

DINIS, P. M.; VASCONCELOS, A. F. C. Modelagem. In: SABRÁ, F. (Org.). Modelagem:

tecnologia em produção de vestuário. 2. ed. Rio de Janeiro: SENAI CETIQT. p. 54-125, 2014.

DPD GROUP. E-shopper barometer 2018. 2019. Disponível em:

$<$ https://www.dpd.com/group/wp-content/uploads/sites/77/2019/03/20190327 e-

shopper barometer 2018.pdf> Acesso em: 19 junho 2019.

swDUBBERLY, H.; PANGARO, P.; HAQUE, U. What is interaction? Are there different types?

Interactions. v. 16, n. 1, 2009.

E-BIT. Relatório Webshoppers 37ª Edição. Fev. 2018. Disponível em:

<http://www.ebit.com.br/webshoppers>. Acesso em: 30 setembro 2018.

GILL, S. A review of research and innovation in garment sizing, prototyping and fitting. Textile

Progress. v. 47, n. 1. p. 1-85, 2015.

GRIBBIN, E. A. Body shape and its influence on apparel size and consumer choices. p. 3-16.

2014. In: Faust, M. E.; Carrier, S. (Eds.). Designing apparel for consumers: The impact of

body shape and size. Woodhead Publishing Series in Textiles: n.151. Philadelphia: Woodhead

Publishing. 2014.

Horn, R. E. Information Mapping. Training in Business and Industry, v. 11, n. 3. 1974.

ISO (International Standard Organization). Standard Sizing Systems for Clothes, (Technical

Report ISO/TR 10652:1991, International Organization for Standardization, Geneva. 1991.

ISO (International Standard Organization). ISO 9241-11:2018. Ergonomics of human-system

interaction- Part 11: Usability: definitions and concepts. (2nd ed.) Genebra: International

Standard Organization. 2018.

ISO (International Standard Organization). ISO 9241-210:210. Ergonomics of human-system interaction- Part 210: human-centered design for interactive systems. Genebra: International Standard Organization. 2010.

KIM, D-E; LABAT, K. An exploratory study of users' evaluations of the accuracy and fidelity of a three-dimensional garment simulation. Textile Research Journal. 2012. 
KIM, M.; LENNON, S. The effects of visual and verbal information on attitudes and purchase intentions in internet shopping. Psychology and Marketing, v. 25, n. 2, p. 146-178, 2008.

LAL, R.; SARVARY, M. When and How is the Internet Likely to Decrease Price Competition? Marketing Science, v. 18, n. 4, p. 485-503, 1999.

LAUFER, D. Are Antecedents of Consumer Dissatisfaction and Consumer Attributions For

Product Failures Universal? Advances in Consumer Research, n. 29, p. 312-317. 2002.

LE BON, C. Fashion marketing: influencing consumer choice and loyalty with fashion products. New York: Business Expert Press, 2015.

MAGRATH, V.; MCCORMICK, H. Marketing design elements of mobile fashion retail apps.

Journal of Fashion Marketing and Management: An International Journal. v. 17, n. 1, p. 115134. 2013.

MASON, A. M.; DE KLERK H. M.; SOMMERVILE J.; ASHDOWN, S. P. Consumers' knowledge on sizing and fit issues: a solution to successful apparel selection in developing countries.

International Journal of Consumer Studies. n. 32, p. 276-284. 2008.

MAVLANOVA, T.; BENUBAN-FICH, R.; KOUFARIS, M. Signaling theory and information asymmetry in online commerce. Information \& management. n. 49, p. 240-247. 2012.

MOGGRIDGE, B. Designing interactions. Cambridge and London: The MIT Press. 2007. MOREIRA, C. S. C.; CASOTTI L. M.; CAMPOS, R. D. Socialização do consumidor na vida adulta: desafios e caminhos para a pesquisa. Cad. EBAPE.BR. v. 16, n. 1. 2018.

NELSON, P. Information and Consumer Behavior. Journal of Political Economy, v. 78, n. 2, p. 311-329. 1970.

NELSON, P. Advertising as information. Journal of Political Economy, v. 82, n. 4, 729-754. 1074.

POSTNORD. E-commerce in Europe 2018. Solna: Postnord. 2018. Disponível em: <https://www.postnord.fi/siteassets/raportit/raportit/postnord-ecommerce-in-europe-2018.pdf> Acesso em: 19 junho 2019.

PREECE, J.; ROGERS, Y.; SHARP, H. Interaction design: beyond human-computer interaction. 4 ed. Chichester: Chichester. 2015.

SEBRAE-RJ. Relatório de Inteligência. Rio de Janeiro: SEBRAE-RJ. 2015. Disponível em: $<$ https://sebraeinteligenciasetorial.com.br/setores/moda/relatoriosde-inteligencia $>$. Recuperado em 30 dezembro 2018.

VITOR, S.; NERY, M. D.; MOREIRA, S. V. A padronização da modelagem como forma de dinamizar as vendas on-line de calças jeans. In: Anais XXXVI Encontro Nacional de Engenharia de Producão. João Pessoa. 2016.

WARD, S.Consumer Socialization. Journal of Consumer Research, v. 1, n. 2, p. 1-14. 1974. Weidner, N. L. Vanity sizing, body image, and purchase behavior: a closer look at the effects of inaccurate garment labelling. Master's Thesis. Eastern Michigan University, Michigan, EUA. 2010.

YOO, J.; KIM, M. The effects of online product presentation on consumer responses: A mental imagery perspective, Journal of Business Research. 2014.

ZWAGA, H. J. G.; BOERSEMA, T.; HOONHOUT, H. C. M. (Eds.). Visual information for everyday use: Design and research perspectives. Philadelphia: Taylor \& Francis e-Library. 2014. 